\title{
Recent Progress in Mercury Research by Young Chinese Scholars
}

\author{
Huan Zhong ${ }^{1,2} \cdot$ Ping $\mathrm{Li}^{3} \cdot$ Jianbo Shi ${ }^{4} \cdot$ Jörg Rinklebe ${ }^{5,6} \cdot$ Xinbin Feng $^{3}$
}

Received: 29 April 2019 / Accepted: 11 May 2019 / Published online: 17 May 2019

(c) Springer Science+Business Media, LLC, part of Springer Nature 2019

China is the largest country of anthropogenic mercury emission (Pacyna et al. 2010). Coal combustion, nonferrous metal smelting, cement production, and iron and steel production (Zhao et al. 2016; Beckers and Rinklebe, 2017) are important emission sectors, which may lead to mercury contamination in terrestrial and aquatic systems. For instance, 1.6\% of studied soil sites in China exceed the limit for mercury, according to a recent national-scale survey by the Ministry of Environmental Protection (MEP) and the Ministry of Land and Resources (MLR) of China (MEP and MLR 2014). The elevated mercury levels in soils could raise ecological and health concerns. Under the context of the Minamata Convention on Mercury, China should take actions to reduce releases of mercury and the related environmental health risks. These challenges in turn call for better understanding of environmental behaviors and risks of mercury, efficient

Huan Zhong and Ping Li have contribute equally to the article.

Xinbin Feng

fengxinbin@vip.skleg.cn

1 State Key Laboratory of Pollution Control and Resource Reuse, School of Environment, Nanjing University, Nanjing, Jiangsu, China

2 Environmental and Life Sciences Program (EnLS), Trent University, Peterborough, ON, Canada

3 State Key Laboratory of Environmental Geochemistry, Institute of Geochemistry, Chinese Academy of Sciences, Guiyang 550081, China

4 State Key Laboratory of Environmental Chemistry and Ecotoxicology, Research Center for Eco-Environmental Sciences, Chinese Academy of Sciences, Beijing 100085, China

5 Laboratory of Soil- and Groundwater-Management, Institute of Foundation Engineering, Water- and Waste-Management, School of Architecture and Civil Engineering, University of Wuppertal, Pauluskirchstraße 7, 42285 Wuppertal, Germany

6 Department of Environment, Energy and Geoinformatics, Sejong University, Seoul 05006, Republic of Korea techniques for remediating mercury-contaminated environment, as well as wisdom in management.

Chinese scholars have made great contributions to mercury research. In the last 20 years, Chinese scholars published 22,444 peer-reviewed papers on mercury-related studies (Web of Science, Timespan: 2000-2019; Topic: mercury; Address: China; by Apr. 29, 2019, the same below), accounting for about $18 \%$ of the total number in the world. The numbers of mercury-related publications from China increased from ' 176 ' in 2000 to ' 1026 ' in 2009 and ' 2320 ' in 2018 . At least $66 \%$ of those publications could be related to environmental and health issues of mercury, with research areas including environmental sciences ecology, public environmental occupational health, and toxicology. Meanwhile, $40 \%$ of the 'highly cited in field' and $75 \%$ of the 'hot papers in field' mercury-related papers in the last 20 years were contributed by Chinese authors. Similarly, $15 \%$ of mercuryrelated papers (i.e. 88 out of 580), published in Bulletin of Environmental Contamination and Toxicology (BECT) since 2000 were from Chinese authors. These numbers provide a hint of the significant contributions of mercury researcher in China, which could be partly attributed to the support of Chinese government.

In view of the active research on mercury, the Young Scholar Forum on Mercury Research (YSF-Hg) was initiated in 2017. The previous two forums were organized by Research Center for Eco-Environmental Sciences, Chinese Academy of Sciences, and Institute of Geochemistry, Chinese Academy of Sciences, with attendees from 11 institutes and universities in the first and 17 in the second forum. Progress in mercury research, particularly with respect to environmental and health concerns and remediation techniques, were presented. Particularly, future directions, such as, identifying microbial methylators in paddy soils, exploring behaviors of $\mathrm{Hg}$ nanoparticles, and comprehensively understanding biogeochemistry of $\mathrm{HgS}$, were discussed. To highlight this progress and to acknowledge YSF-Hg, we proposed this special issue, inviting attendees and mercury researchers to contribute review and research papers, 
focusing on recent progress made in environmental studies of mercury.

In this issue of BECT, we have included 15 reviews and 3 research papers, covering key topics of mercury research, e.g., mercury methylation and demethylation, bioaccumulation and toxicity, food safety and health issues, mercury biogeochemistry and risks in different environments (e.g., atmosphere, forest, mountain, farming soil, aquaculture sites, freshwater and marine systems, and municipal systems), human activity-impacted mercury cycling, as well as novel techniques for mitigating risks of mercury. This issue could be a milestone of $\mathrm{Hg}$ research in China, and would suggest future avenues of research. While much progress has been made in the last tens of years in understanding biogeochemistry and risk of $\mathrm{Hg}$, there is still a long road ahead.

\section{References}

Beckers F, Rinklebe J (2017) Cycling of mercury in the environment: sources, fate, and human health implications-a review. Crit Rev Environ Sci Technol 47(9):693-794

Ministry of Environmental Protection (MEP) and the Ministry of Land and Resources (MLR). National survey bulletin soil pollution, China. 2014. http://www.gov.cn/foot/2014-04/17/content_26617 68.htm.

Pacyna EG, Pacyna JM, Sundseth K, Munthe J, Kindbom K, Wilson S, Steenhuisen F, Maxson P (2010) Global emission of mercury to the atmosphere from anthropogenic sources in 2005 and projections to 2020. Atmos Environ 44(20):2487-2499

Zhao L, Qiu G, Anderson CWN, Meng B, Wang D, Shang L, Yan H, Feng X (2016) Mercury methylation in rice paddies and its possible controlling factors in the $\mathrm{Hg}$ mining area, Guizhou province Southwest China. Environ Pollut 215:1-9 